\title{
An experimental study on the key fretting variables for flexible
}

\section{marine risers}

\author{
S.M. O’Halloran ${ }^{1}$, A.M. Harte ${ }^{2}$, P.H. Shipway ${ }^{3, \text { a }}$, S.B. Leen ${ }^{1, a^{*}}$ \\ ${ }^{1}$ Mechanical Engineering, National University of Ireland, Galway, Newcastle Rd., Galway, H91 HX31, \\ Ireland \\ ${ }^{2}$ Civil Engineering, National University of Ireland, Galway, Newcastle Rd., Galway, H91 HX31, Ireland \\ ${ }^{3}$ Faculty of Engineering, The University of Nottingham, Nottingham, NG7 2RD, UK
}

\begin{abstract}
This paper presents an experimental investigation into the effects of contact conformity, contact pressure and displacement amplitude on the gross-slip fretting behaviour greaselubricated cylinder-on-flat contacts in the context of flexible marine riser pressure armour wire, and compares behaviour with that observed in unlubricated conditions. Characterisation of friction and wear is critical to fretting fatigue life prediction in flexible risers since friction directly controls trailing-edge fretting stresses and hence fatigue crack initiation, on the one hand, and on the other hand, directly affects wear via relative tangential slip (displacement). Wear can have a beneficial or detrimental effect on fatigue crack initiation and propagation, depending on relative slip and slip regime. It is shown that friction and wear are higher for dry conditions than for grease-lubricated conditions. For grease-lubricated conditions, behaviour is determined by whether grease can be retained in the contact (as opposed to being extruded out). Retention (or replenishment) of grease in the contact results in low rates of wear and low
\end{abstract}


coefficients of friction; these conditions are favoured by fretting displacements above a critical value, by low contact conformity, and by low applied loads.

Keywords: Fretting wear, experimental, grease-lubrication, contact geometry, slip amplitude, flexible risers, pressure armour layer, nub-groove.

*Author for Correspondence: Prof. Sean Leen (sean.leen@ nuigalway.ie)

a Prof. Sean Leen and Prof. Philip Shipway: Joint senior authors

\section{Introduction}

Fretting is defined as surface damage that occurs between contacting bodies under normal load combined with micro-scale relative oscillatory motion. Vingsbo and Söderberg [1] mapped the dependency of fretting damage on slip amplitude and normal load and demonstrated that fretting fatigue (cracking) is the dominant damage mechanism in the partial slip regime but, as slip amplitude increases, fretting wear becomes the dominant mechanism in the gross slip regime. This leads to an increase in component life due to the redistribution of stresses as wear takes place [2], and as embryonic cracks are worn away before propagation [3]. In fretting, the retention or ejection of debris developed in the contact area also influences the magnitude and mechanism of wear damage [4].

Fretting wear is a complex damage process; Dobromirski proposed that there are up to 50 variables that affect fretting behaviour [5]. The fretting process includes multiple physical phenomena such as asperity contact, causing plastic deformation and damage, oxidation of 
wear surface material and debris behaviour (covering its retention in the contact and/or removal from the contact). Most experimental studies on fretting are based on simplified contact geometries, such as cylinder-on-flat, crossed cylinders or flat-on-flat [6]. It has been demonstrated [7-9] that the specific wear rate is dependent on the radius of curvature for cylinder-on-flat and ball-on-flat for unlubricated fretting. It is difficult to model the full complexity of fretting using computer models; however, a number of authors [10-13] have developed finite element fretting wear models to predict the geometrical development of a contact in fretting, normally assuming that the specific wear rate itself is a constant.

There are many methods for reducing friction (thus, commonly resulting in a reduction or elimination of fretting damage and wear) while still allowing relative displacement between contacting surfaces; these include lubrication, surface texturing or thin film coating. Different forms of lubrication are used to reduce fretting damage, such as solid (powder graphite, polymeric film), liquid (oil) or semi-solid (grease) lubricants. However, where the contact slip amplitude is small, the desired lubricant penetration into the fretting contact can be limited. McColl et al. [14,15] investigated the effect of lubricant viscosity and slip amplitude. It was demonstrated that for grease-lubricated contacts, the fretting regimes depend on pressure and the penetration of the lubricant into the contact zone, and hence, on the formation of a lubricant tribofilm. Zhou et al. [16,17] showed that, in lubricated fretting, the higher the viscosity of the lubricant, the slower the transition towards a low tribofilm-lubrication interface. It was also shown that the coefficient of friction depends on slip amplitude for grease-lubricated fretting: lower friction values were observed for tests carried out with larger slip amplitudes. Recently, Haviez [18] quantified the tribological response of grease-lubricated fretting contacts using a friction energy wear approach for partial slip, gross slip and near reciprocal sliding cases. It was shown that for grease-lubricated fretting, wear volume is mainly controlled by metal-on- 
metal contact and can be rationalised using a modified effective friction work approach. Fretting damage mechanisms and rates are dependent on oxygen penetration into the contact area $[16,19]$. Wright $[19]$ found that the concentration of oxygen in air is about six times that in an oil-based lubricant and that the rate of oxygen diffusion within lubricant is approximately proportional to the inverse of its viscosity, indicating that lubricants significantly limit oxygen ingress into the contact. Neyman and Sikora [20] have shown that for fretting contacts with higher viscosity lubricants, higher wear rates are observed; this was attributed to the exclusion of oxygen from the contact, restricting the production of beneficial oxidised wear particles, (which reduce the wear rate since wear particles are less abrasive than steel-on-steel fretting). Similarly, grease lubrication has been shown to restrict oxygen from the contact area, thus preventing oxide-based debris from developing [14,21]. Moreover, the presence of lubricant at the fretting contact also hinders the escape of debris from the contact [20].

Flexible marine risers are a key component in the delivery of offshore hydrocarbons from the seabed to sea level, typically to a floating structure, such as a platform or vessel. Flexible risers rely on a complex, composite cross-sectional architecture of helically-wound, interlocking steel wires and polymer layers to give a unique combination of high bending flexibility, axial and torsional stiffness and internal pressure resistance, as well as internal and external corrosion resistance (see Figure 1). Due to the geometrical and loading conditions of the nub and groove feature of the pressure armour layer, it can be susceptible to fretting damage (see Figure 2). For the inter-locking pressure armour steel wires, micro-articulation of nub and groove mechanical contacts plays a key role in achieving flexible structural properties of the riser, while also allowing for extraction of hydrocarbons from deep water (high pressure environments). Normal forces due to internal fluid and external hydrostatic pressure and an additional outer pressure due to the tension of the helically wound tensile armour wires keep 
the nub and groove of the pressure armour in contact. Micro-scale relative displacement can occur due to global riser bending moments, for example, caused by sea-state loading and vessel motions.

The pressure armour wire represents a critical aspect of riser design [22-24]. The problem of fretting fatigue in flexible marine risers has received relatively little attention. Researchers have presented analytical solutions to calculate stresses, contact pressures and slip between layers for flexible pipes [25-27]. More recently, Perera [28] presented an experimental investigation for grease-lubricated fretting of the pressure armour layer of unbonded flexible pipes, concluding that the issue requires further investigation. Previous work by the current authors $[29,30]$ has focused on finite element modelling of the nub-groove fretting wear contact using adaptive meshing techniques and multi-axial fatigue life predictions. Increased coefficient of friction was predicted to have a detrimental effect on fretting fatigue life to crack initiation [29]. In gross-slip conditions, increased wear was shown to have a beneficial effect on predicted crack initiation life due to redistribution of stresses [30]. Little or no experimental research has been presented on fretting fatigue in flexible marine risers; therefore, this paper investigates the effects of key fretting variables for fretting of flexible risers under dry and lubricated conditions.

In practice, a lithium $(\mathrm{Li})$-based grease is used in the laying process of the helically wound wire around the riser; this grease can remain in the nub-groove region during the service life of the riser. Thus, an experimental investigation has been conducted here to (i) characterise the dry fretting wear behaviour, and (ii) investigate the effect of a Li-based grease lubricant on the fretting wear behaviour, of representative pressure armour layer material. This experimental methodology considers both dry and grease-lubricated contacts for two different cylinder-onflat contact conformities under various normal loads, combined with different tangential 
displacements, which are representative of the nub-groove fretting contact of flexible marine riser pressure armour wire [29-31] (Figure 2).

\section{Experimental procedure}

\subsection{Materials, test conditions and procedures}

The pressures investigated represent the pressure in an equivalent round-on-flat nubgroove contact (see Figure 3) in a flexible marine riser under internal pressures of 7 and 14 $\mathrm{MPa}$ and no external pressure. These internal pressures are typical sample pressures from the range of operating pressure for this design of production- service riser. However, under dynamic riser operating conditions, the pressure may vary due to an effect known as "slugging", which is caused by variations in the internal fluid density causing variations in internal pressure. Therefore, in risers, the normal loading due to internal pressure may not be constant, as assumed here. More specifically, these loading conditions correspond to the vessel hang-off point of the riser, based on dynamic analyses of the riser in previous work [31]. The contact pressure was determined for the nub-groove contact of marine risers using a finite element axisymmetric model, as described previously [29]. Fretting behaviour is, of course, affected by local contact pressure; therefore, in this study, different combinations of two normal loads and two cylinder radii were used to investigate a range of contact pressure distributions. The contact displacements investigated here are representative of gross slip conditions [31] that would occur in areas of the riser that experience large dynamic curvature due to wave and current loading conditions, such as near bend stiffeners, at the vessel hang-off point and at seabed touch-down. In a flexible riser, for a given internal fluid pressure and external hydrodynamic pressure, the relationship between nub-groove contact displacement and riser 
curvature is dependent on the nub-groove coefficient of friction. Hence, coefficient of friction is an important variable in the fretting analysis and design of pressure armour wire in flexible risers.

Fretting wear experiments were conducted on 080M40 steel with essentially the same chemical composition and hardness as that used in the pressure armour layer of flexible marine risers (see Table 1). A general-purpose grease (AFB-LF Grease, THK), developed with a Libased consistency enhancer, using refined mineral oil as the base oil, was used as the lubricant throughout this work. The test methodology employed was based on ASTM standard test methods [32,33].

A cylinder-on-flat specimen configuration was used to represent the pressure armour wire nub-groove contact, as illustrated in Figure 4. The flat and cylindrical specimens were ground on a linear and cylindrical grinder, respectively, giving a roughness $\left(R_{\mathrm{a}}\right)$ of 0.1 to 0.3 $\mu \mathrm{m}$ for the flat specimen and of 0.4 to $0.7 \mu \mathrm{m}$ for the cylindrical specimen. These values for specimen roughness are representative of that of the nub-groove contacts in flexible risers, as measured via profilometry on pressure armour material extracted from a pre-service riser. The fretting test rig used is described in detail elsewhere [9,34,35]. The flat specimen is mounted on the lower specimen mounting block (LSMB) which is stationary and the cylindrical specimen is mounted on the upper specimen mounting block (USMB) [34]. For the lubricated tests, grease was applied to both the flat and cylindrical specimen before the specimens were brought into contact. No further lubrication was applied during the testing process; this represents the method by which grease can enter the nub-groove contact region of flexible risers. A dead-weight and lever configuration was used to load the USMB, resulting in a normal load, $P$, being applied to the (cylindrical) specimen. The layout and components of the rig can 
be seen in Figure 5. The linear displacement of the cylindrical specimen is achieved via the USMB using an electromagnetic vibrator (EVM). The displacement of the USMB (cylindrical specimen), $\Delta$, is monitored and controlled throughout the test using a capacitance displacement sensor mounted on the LSMB, to achieve a specific displacement amplitude, $\Delta^{*}$.

The tangential force, $Q$, is measured and recorded throughout the test by a piezoelectric load cell which is connected to the quasi-stationary LSMB (see Figure 5). Both displacement and load sensors have been calibrated (both externally and in-situ) under static conditions. The load and displacement signals are sampled at a rate of two hundred measurements per fretting cycle for all of the experiments [34].

Real-time visualisation of the fretting loops allows for monitoring of the fretting contact behaviour throughout the test. A gross-slip fretting loop is shown in Figure 6. The measured displacement amplitude, $\Delta^{*}$, is always slightly larger than the contact slip amplitude, $\delta *$ due to rig compliance and elastic deformation of the specimen since the fretting contact region is separated from the location of the displacement sensor. $\delta *$ can be derived by measuring the displacement at zero force, as illustrated Figure 6. There are many methods of measuring the coefficient of friction [36-38]. In this work, the ECoF parameter proposed by Fouvry et al. [37], is used. It was observed [37] that the tangential force does not remain constant through the sliding part of the fretting loop, as illustrated in Figure 6, and thus proposed that the energy dissipated per cycle could be used to define a coefficient of friction which is more representative of the overall behaviour of the contact. The energy coefficient of friction (ECoF) [37] is defined as follows

$$
E C o F=\frac{E_{d}}{4 P \delta^{*}}
$$


where $E_{\mathrm{d}}$ is the dissipated energy per cycle (area of the fretting loop, see Figure 6) [37].

Cylinder-on-flat fretting tests were conducted with cylinder radii, $R$, of $6 \mathrm{~mm}$ (lessconforming contact pairs) and $160 \mathrm{~mm}$ (more-conforming contact pairs). The flat specimen has a width, $W$, of $10 \mathrm{~mm}$, as seen in Figure 4 (this defines the contact length). Experiments were conducted for a range of normal loads, $P$, and applied displacement amplitudes, $\Delta^{*}$, as summarised in Table 2. The experiments were conducted with and without grease lubricant at ambient temperature (typically $22^{\circ} \mathrm{C}$ ), at a frequency of $20 \mathrm{~Hz}$, for a duration of 100,000 cycles.

\subsection{Estimation of wear volume and surface topography}

Following the methodology described previously [9,35], the test specimens were swabbed lightly with methylated spirit to remove loose debris and residual grease after testing. The profile of the wear scar on each specimen was scanned and measured using a Bruker Contour GT-I interferometer (vertical resolution $\sim 0.15 \mathrm{~nm}$ and lateral resolution of $4 \mu \mathrm{m}$ ). The scan area is depicted in Figure 7; the scan area includes part of the unworn surface (away from the wear scar). This allows for a reference surface to be defined [39] (see Figure 8). Specific wear and transfer rates for the contact pair are calculated as follows:

$$
\begin{aligned}
& \frac{d V^{-}}{d N}=\frac{V^{-}}{4 P N \delta^{*}} \\
& \frac{d V^{+}}{d N}=\frac{V^{+}}{4 P N \delta^{*}}
\end{aligned}
$$


where $\delta^{*}$ is the average test slip amplitude, $P$ is the normal load, $N$ is the number of cycles per test, $V^{-}$and $V^{+}$are the total wear and transfer volumes, respectively, for the contact pair, given by:

$$
\begin{aligned}
& V^{-}=V_{\text {flat }}^{-}+V_{c y l}^{-} \\
& V^{+}=V_{f l a t}^{+}+V_{c y l}^{+}
\end{aligned}
$$

where $V_{\text {flat }}^{-}$and $V_{c l y}^{-}$are the volumes of the void below each reference surface is the wear volume for the flat and cylindrical specimens, respectively (see Figure 8). Similarly, $V_{\text {flat }}^{+}$and $V_{c y l}^{+}$are the volume of (transferred) material above the reference surfaces for the flat and cylindrical specimens, respectively (see Figure 8). Note that this may contain displaced metal or oxide debris, and therefore, may be originally from either specimen. Micro-galling, described as the localised damage caused by the occurrence of solid-phase welding between sliding surfaces $[40,41]$, may also take place. This causes severe wear, including surface tearing and material transfer between specimens.

Since this work focusses on the effect of loading conditions, contact conformity and lubrication on fretting wear behaviour of pressure armour material, it is essential to determine the error associated with calculating the specific wear rates. This allows for any differences to be deemed significant or irrelevant. The overall error associated with the specific wear rate, based on the errors of the individual input factors, [42], for a given function, $F$, with $n$ independent variables, $u_{1}, u_{2}, \ldots u_{\mathrm{n}}$. 


$$
F=f\left(u_{1}, u_{2}, \ldots, u_{n}\right)
$$

and with errors of $\pm \Delta u_{1}, \pm \Delta u_{2}, \ldots, \pm \Delta u_{n}$, for the individual variables, is given by:

$$
E_{\text {overall }}=\sqrt{\left(\Delta u_{1} \frac{\delta f}{\delta u_{1}}\right)^{2}+\left(\Delta u_{2} \frac{\delta f}{\delta u_{2}}\right)^{2}+\ldots+\left(\Delta u n \frac{\delta f}{\delta u_{n}}\right)^{2}}
$$

For the specific wear rate, errors in $V^{-}, P$ and $\delta^{*}$ were considered. Using Equations (2) and (7), the probable overall error is:

$$
E_{\text {overall }}=\sqrt{\left(\Delta V^{-} \frac{1}{4 P N \delta_{1}^{*}}\right)^{2}+\left(\Delta P \frac{-V^{-}}{4 P^{2} N \delta^{*}}\right)^{2}+\left(\Delta \delta^{*} \frac{-V^{-}}{4 P^{2} N\left(\delta^{*}\right)^{2}}\right)^{2}}
$$

where $\pm \Delta V^{*}, \pm \Delta P$ and $\pm \Delta \delta^{*}$ are the errors associated with $V^{-}, P$ and $\delta^{*}$, respectively. $\pm \Delta V^{*}$ was the wear volume measured for a nominally flat surface using the method described above, calculated as $1.4 \times 10^{-7} \mathrm{~mm}^{3} . \pm \triangle P$ was estimated to be $\pm 1 \mathrm{~N}$, and $\pm \Delta \delta^{*}$ was the maximum deviation of $\delta^{*}$ from the average $\delta^{*}$ throughout the tests. The dominant issue of uncertainty in the calculation of specific wear rate is the value of $\pm \Delta \delta^{*}$ for each test. The value of $\pm \Delta \delta^{*}$ increases for lower applied displacements (i.e. $\Delta^{*}=15 \mu \mathrm{m}$ ), thus, increasing the possible error in the calculation of specific wear rate for these tests.

\subsection{Characterisation of wear scars and debris}

The nature of the fretting wear scars was characterised using scanning electron

microscopy (SEM) (Philips XL30 SEM). Back scattered electron (BSE) images were used to distinguish oxide from metallic material $[9,35]$. Iron oxide (debris which forms in the wear scar) has a lower average atomic number, and therefore appears darker in the BSE image than 
the steel. The identification of oxide was confirmed qualitatively by energy-dispersive X-ray spectroscopy (EDX) analysis.

\section{Results}

\subsection{Effect of lubrication}

Figure 9 shows the development of ECoF over the duration of the tests for $R=6 \mathrm{~mm}$ with $P=250 \mathrm{~N}$, for the dry fretting cases. An initial rapid rise in ECoF was observed over the first $\sim 500$ cycles; this then falls gradually to a steady value over the next $\sim 9000$ cycles. Similar results were observed for all dry fretting tests. The measured range of stabilised ECoF for all unlubricated tests was from 0.61 to 0.68 , indicating little effect of tangential displacement for the tested conditions.

Figure 10(a) shows the development of ECoF over the duration of the tests for $R=6$ mm with $P=250 \mathrm{~N}$, for grease-lubricated cases. A significant effect of tangential displacement was observed; specifically, ECoF was found to decrease with increasing tangential displacement. Comparison of Figure 10(a) and Figure 10(b) suggests that extrusion of grease from the contact increases for larger normal load $(500 \mathrm{~N})$ i.e. ECoF value rises faster. At the lower load (Figure 10(a)), a steady ECoF of 0.12 was measured for displacement of $50 \mu \mathrm{m}$, whereas, at lower displacements (30 and $15 \mu \mathrm{m}$ ), the ECoF was higher and more unsteady. The ECoF values after $10^{5}$ cycles were $0.26 \pm 0.08$ at $30 \mu \mathrm{m}$ and $0.40 \pm 0.18$ at $15 \mu \mathrm{m}$. The detrimental effect of low tangential displacement $(15 \mu \mathrm{m})$ is observed for the higher normal load $(500 \mathrm{~N}$ ) test also (Figure $10(\mathrm{~b})$ ) where a low ECoF value of $\sim 0.13 \pm 0.08$ was measured for displacement of $50 \mu \mathrm{m}$, but at lower displacements (30 and $15 \mu \mathrm{m}$ ), the ECoF was higher 
and more unsteady. The ECoF values after $10^{5}$ cycles were $0.21 \pm 0.49$ at $30 \mu \mathrm{m}$ and $0.38 \pm$ 0.4 at $15 \mu \mathrm{m}$. Overall, this suggests that lubrication retention in the contact is promoted by lower normal load and larger tangential displacements. The most detrimental case is the combination of high normal load $(500 \mathrm{~N})$ and low tangential displacement $(15 \mu \mathrm{m})$. As can be seen in Figure 10(b), this case gives more unsteady and large ECoF values.

Specific wear rates for tests with $6 \mathrm{~mm}$ radius cylindrical specimens are presented in Figure 11. For dry tests, the specific wear rate increases with tangential displacement. However, for grease-lubricated conditions, specific wear rate falls as displacement amplitudes increases. At lower normal load $(250 \mathrm{~N})$, the dry specific wear rates were higher than greaselubricated values (Figure 11(a)) at all displacement amplitudes. However, slightly higher specific wear rates were observed for lubricated tests at higher normal load $(500 \mathrm{~N})$ and at lower displacements $(15 \mu \mathrm{m}$ and $30 \mu \mathrm{m})$ than for the corresponding dry cases (see Figure 11(b)).

Figure 12(a) presents the average 2D wear scar across the worn flat specimen surfaces for both dry and grease-lubricated tests conducted with $6 \mathrm{~mm}$ radius cylindrical specimens with a normal load of $250 \mathrm{~N}$ and a displacement amplitude of $50 \mu \mathrm{m}$. Figure 12(b, c) presents BSE images of the fretting wear scars on these flat specimen. The damage is reduced considerably for the grease-lubricated condition compared to the dry condition; in dry conditions, extensive damage can be observed with the surface being largely covered with an oxide debris layer, whereas in the lubricated case, there is evidence of only very slight damage and no evidence of any oxide debris formation. 


\subsection{Effect of contact geometry}

Figure 13 presents the effect of applied displacement on evolution of ECoF for a more conforming contact geometry $(R=160 \mathrm{~mm})$ with the same normal loads examined in the tests with the less conforming contacts $(R=6 \mathrm{~mm})$ (presented in Figure 10). It was observed that, for grease-lubricated cases at both of the applied loads examined, full lubrication (as observed for tests with $R=$ the $6 \mathrm{~mm}$ and a displacement amplitude of $50 \mu \mathrm{m}$ (see Figure 10)) was not observed at either applied load. Hence, the test matrix was extended to a higher displacement amplitude $(100 \mu \mathrm{m})$. With the inclusion of this higher displacement amplitude, the general behaviour for the more-conforming contacts is observed to be very similar to that observed with the less-conforming contacts, namely that a low value of ECoF can only be maintained once the applied displacement amplitude is greater than a certain value. Moreover, in cases where a low value of ECoF cannot be maintained, $\mathrm{ECoF}$ rises more quickly with higher applied load and with lower applied displacement amplitude. It is also notable that in these cases, the rate at which ECoF rises is lower for the more-conforming contacts (Figure 13) than it is for the less-conforming contacts (Figure 10).

The specific wear rates for tests with the more-conforming contact geometry $(R=160$ $\mathrm{mm}$ ) are presented in Figure 14 for the lubricated tests (with values for the unlubricated tests presented alongside to provide context). For grease-lubricated cases with high ECoF values, viz. with displacement amplitudes of $15 \mu \mathrm{m}$ and $30 \mu \mathrm{m}$ (see Figure 13), the specific wear rate is higher than or close to the corresponding dry fretting tests. The specific wear rate decreases significantly (by around an order of magnitude) for the grease-lubricated tests at the largest amplitudes. 
Average 2D wear scars across the worn flat specimen surfaces following greaselubricated tests with the more-conforming contact geometry $(R=160 \mathrm{~mm})$ are presented in Figure 15(a). BSE images of sample fretting wear scars on the flat specimens for these tests are presented in Figure 15(b, c, d). With higher loads, lubrication becomes less effective and more fretting damage is observed. However, increasing tangential displacement from $50 \mu \mathrm{m}$ to $100 \mu \mathrm{m}$ reduces the damage considerably.

\subsection{Durability of the low friction conditions}

Low friction and damage has been observed under certain conditions in the tests run for $10^{5}$ cycles reported in this paper. In other cases, following $10^{5}$ cycles, ECoF had risen to high values (around 0.5) whereas in other cases, it had risen from its baseline (fully-lubricated) value, but was still relatively low. As such, two cases were selected for extended testing to examine how ECoF would continue to develop. Tests were conducted with both $6 \mathrm{~mm}$ and 160 $\mathrm{mm}$ radius specimen under $250 \mathrm{~N}$ normal load and $50 \mu \mathrm{m}$ tangential displacement for $10^{6}$ cycles; Figure 16 shows the development of ECoF for these tests. A constant and low value of ECoF of $\sim 0.12$ was observed for the less-conforming contact $(R=6 \mathrm{~mm})$ with no indication of any changes over this test duration. For the more-conforming contact $(R=160 \mathrm{~mm})$, the ECoF rises (consistent with the results plotted in Figure 13(a)) and continues to do so, reaching a value of $\sim 0.24$ at around $6.5 \times 10^{5}$ cycles, whereupon it continually fell to a value of $\sim 0.18$ after $10 \times 10^{5}$ cycles. 


\section{Discussion}

The ECoF values after $10^{5}$ cycles for grease-lubricated tests are lower than the values for dry tests, as shown in Figure 9, 10, 13. The ECoF values for dry tests are broadly independent of loading conditions and conformity. The initial ECoF values were in the range 0.4 to 0.6 ; this is attributed here to material transfer and adhesion during metal-on-metal contact (see dry fretting wear profile and compacted oxide layer, shown as darker grey, in BSE image of Figures 12a and 12b). An increase in ECoF (up to 0.79 after between 10 and 100 cycles) was then observed due to abrasive action during the accumulation of oxidised debris. Upon development of a compacted debris layer, the ECoF stabilised to a constant value of between $\sim 0.60$ and 0.68 after $\sim 4 \times 10^{4}$ cycles, with the ECoF itself beings relatively insensitive to applied displacement and normal load.

In contrast, the results for lubricated-fretting tests show that the fretting behaviour depends more significantly on loading conditions and contact geometry (see Figures 10 and 13). For a lubricant to provide effective protection, it must (i) penetrate the contact, and (ii) remain in the contact area to provide a protective film. It was previously shown [43] for oillubricated fretting that the concept of covered width can be used to identify regimes of fretting behaviour where the oil is continuously replenished into the contact area to provide a protective tribofilm; in this work, it was argued that lubrication was only effective when the covered width (i.e. the width of contact which never comes out of contact throughout a fretting stroke) fell to zero. However, in the current work with a grease lubricant, this does not appear to be applicable; full and stable lubrication is observed for the following cases: (i) $R=6 \mathrm{~mm}, P=$ $250 \mathrm{~N}$ and $\Delta^{*}=50 \mu \mathrm{m}$; (ii) $R=160 \mathrm{~mm}, P=250 \mathrm{~N}$ and $\Delta^{*}=100 \mu \mathrm{m}$; (iii) $R=160 \mathrm{~mm}, P=$ 
$500 \mathrm{~N}$ and $\Delta^{*}=100 \mu \mathrm{m}$. And in these three cases, the covered width is greater than zero (the smallest value of the covered semi-width is for the first of these three cases where it is $16 \mu \mathrm{m}$ ).

Despite the failure of this concept to describe the behaviour of fretting in grease lubricated conditions, there are obvious trends in the behaviour observed. There is a clear link between the applied displacement and the evolution of ECoF with fretting cycles (shown in Figure 10 and Figure 13). For the less conforming contact ( $6 \mathrm{~mm}$ radius), friction is low in all cases initially (see Figure 10). For the smallest tangential displacement $(15 \mu \mathrm{m})$ the lubricant is pushed out of the contact by the fretting action which results in a rise in $\mathrm{ECoF}$ and wear rate which is approximately the same as that observed in the dry case (Figure 11). As tangential displacement is increased to $30 \mu \mathrm{m}$, the evolution of ECoF indicates that it takes longer (more fretting cycles) to remove the lubricant from the contact (Figure 10) and the wear rate is correspondingly smaller (Figure 11). At a tangential displacement of $50 \mu \mathrm{m}$, the ECoF indicates that the lubricant is effectively retained in the contact (Figure 10), and that this behaviour appears to be stable for the long-term (Figure 16); there is also a commensurate reduction in specific wear rate (Figure 11). In addition, it is clear that the extrusion of grease is more rapid as the applied load is increased.

Comparison of Figure 10 and Figure 13 indicates that for the more conforming contact (160 $\mathrm{mm}$ radius), it takes longer (more fretting cycles) to extrude the grease out of the contact, i.e. the rise in $\mathrm{ECoF}$ takes longer than for less conforming contacts due to the larger distances over which the grease must be extruded (larger elastic contact width) and the lower contact pressures. Again, with the more-conforming contacts (Figure 13 and 14), it is observed that the extrusion of grease from the contact occurs at low applied displacements and is accelerated by increased normal load. For the more-conforming contact, full and stable grease lubrication, resulting in low specific wear rate and coefficient of friction, requires a higher displacement 
amplitude $(100 \mu \mathrm{m})$ than was required for the less-conforming contact $(50 \mu \mathrm{m})$. However, an extended test of a more-conforming contact where ECoF had been seen to initially rise $\left(\Delta^{*}=\right.$ $50 \mu \mathrm{m}$ and $\mathrm{P}=250 \mathrm{~N}$ ) demonstrated that changes in surface morphology due to fretting could result in that contact developing a state of full and stable lubrication (Figure 16).

For fretting design of the nub-groove contact in flexible risers, reliable determination of $\mathrm{ECoF}$ is important for sliding regime and fatigue stresses. If friction is over-estimated, this will lead to under-prediction of contact slip and hence, slip regime (i.e. partial slip instead of gross slip conditions). In contrast, if friction is under-estimated, slip will be over-predicted, leading to possible over-prediction of fatigue life (in gross slip regime) if beneficial wear effects are accounted for [30].

Jin and Mall [44] have presented an experimental study on the effects of contact geometry and normal load (for a rounded punch-on-flat and a round-on-flat) on the fretting fatigue (with substrate fatigue load) behaviour of Ti-6Al-4V. It was shown that (minimum) fretting fatigue life is independent of contact geometry and normal load. It is convenient to consider fretting damage as having two contributions, a tribological contribution and a mechanical contribution. The present paper has highlighted the dependence of tribological effects of conformity (and other variables), highlighting, in particular, the beneficial effects of less conforming contacts (lower contact widths) under grease lubrication conditions for friction and wear. Previous FE predictions by the authors [29] have shown that low values of nubgroove coefficient of friction (e.g. $\mathrm{ECoF}=0.1)$ increase fretting fatigue life by up to $10^{7}$ cycles in comparison to high values (e.g. $\mathrm{ECoF}=0.8$ ). In contrast, however, previous work by Zhang et al. [45], for example, demonstrated the detrimental effect of smaller contact conformity (width) on the mechanical contribution to fretting damage (including the mechanical effects of wear), on the assumption of friction (and specific wear rate) being independent of contact 
conformity. It is suggested here that, on the one hand, smaller contact width leads to decreased tribological damage under grease-lubrication conditions, whereas, on the other hand, a smaller contact width leads to increased mechanical damage; these opposing effects may (in certain situations) cancel each other out, which is consistent with the observation of Jin and Mall [44] of a negligible overall effect on minimum fretting fatigue life.

The present paper has highlighted the effects of contact conformity and displacement amplitude on tribological damage for flexible riser design. It is clear that, in order to reliably design for optimum fatigue life in flexible risers, both tribological and mechanical aspects need to be considered. This can potentially be achieved by designing the riser nub-groove conformity so that the contact width is small compared to the nub-groove displacement, and hence, low coefficient of friction values will be achieved under grease-lubricated conditions, but subject to analysis of the mechanical damage implications.

Future studies could investigate other possible phenomena including the effects of evolving wear profile on measurements of contact displacement, as well as oxidation and local temperature changes on fretting behaviour of nub-groove contacts. The use of $\delta^{*}$ as opposed to the applied displacement, $\Delta^{*}$, reduces the possible error associated with the changes in contact displacement due to wear. Jin et al. [38] recently developed a geometry independent coefficient of friction, that is independent of rig stiffness and evolving wear scar geometry. Oxidation and local contact surface temperature effects are more difficult to measure. The local temperature is expected to increase in the contact region due to frictional forces and frequency of testing; this can cause the lubricant to become more viscous, thus increasing the possibly of oxidation. Jin et al. [35] showed that local temperature increase due to dissipated energy is dependent on test frequency, ECoF, displacement amplitude and pressure distribution. The tests conducted in this paper were at a frequency of $20 \mathrm{~Hz}$; using a simplified model, based on 
convection [35], the estimated maximum increase in contact temperature is $\sim 5.5^{\circ} \mathrm{C}$ (for $\Delta^{*}=$ $50 \mu \mathrm{m}, \mathrm{ECoF}=0.7$ and $P=500 \mathrm{~N}$ after $10^{5}$ cycles $)$. However, this simplified model also shows that the evolving contact pressure due to wear will slightly decrease the rate of temperature increase. Oxidation of particles is both temperature and time dependent. Increased friction heat also promotes oxidation of debris particles [46]. The evolving wear scar will retain debris particles more readily than the initial flat surface; this will help to promote the formation of a stable compacted oxide layer, which can act as a third body, reducing wear [13,47]. The oxygen ingress to the wear scar can occur more easily for dry fretting than for grease-lubricated, since the concentration of oxygen in air is about six times that in an oil-based lubricant [19]. It was also found that for lubricated fretting, oxidation is inversely proportional to the viscosity of the lubricant [19]. Therefore, local increase in temperature due to frictional energy is expected increase oxidation by reducing viscosity. Fouvry et al. [48] has shown that the ease at which oxidation occurs in the contact region can influence the wear scar morphology and wear rates. For low contact pressure, low test frequency and small contact size with a varying normal load, increased the oxidation in the contact and a U-shaped wear scar was observed. For increased contact pressure, test frequencies and contact sizes, oxidation was reduced in the center of the contact. This promoted metal-on-metal adhesion, transfers and tribologically transformed zones in the center of the contact; hence W-shaped wear scars and low wear rates were observed.

It is possible that grease extrusion is restricted in the flexible marine riser due to the nub-groove geometry (flat groove that is curved away from the contact) or due to the lay angle of the pressure armour wire in the risers (see Figure 4). Future work will experimentally investigate the effect of various nub-groove geometries on grease-lubricated fretting. These geometries will include conforming contacts (round nub in round groove) and also nubs of 
varying radius, designed to minimise the effect of additional contact pressure due to global riser bending. Full scale riser or sub-element representative (e.g. see [49-51]) testing could provide further insight into the extrusion of grease in the realistic flexible riser closed structure (e.g. see [52] for testing of lubricated fretting in laboratory scale spline couplings); this testing could possibly also be designed to include effects of gravity which may act in different directions relative to the nub-groove contact, thus affecting grease-lubrication if the global riser is vertical (see Figure 1).

\section{Conclusions}

An experimental characterisation of key design variables relevant to fretting in the pressure armour wire of flexible marine risers is presented, with a specific focus on grease lubrication, contact conformity, relative tangential displacement and normal load. Fretting performance is assessed with respect to friction and wear via three-dimensional profilometry and scanning electron microscopy with back-scatter for gross slip, displacement-controlled conditions. Quantitative measures include evolutions of energy coefficient of friction and specific wear rate. Key conclusions from the work are as follows:

- Under dry conditions, friction is found to be relatively insensitive to increasing tangential displacement and specific wear rate increases with tangential displacement. Under grease-lubricated conditions, friction and specific wear rate are found to decrease with increasing displacement, particularly for the larger displacements tested. 
- Grease lubrication is shown to be generally beneficial to the fretting behaviour of the tested material, resulting in lower friction and specific wear rates than dry fretting cases.

- For grease lubrication, there is a threshold value of displacement, above which friction and specific wear rate remain low. It was also found that as the contact becomes more conformed, this threshold value increases significantly.

- Grease extrusion out of the contact is accelerated by increased normal load and by reduced contact conformity.

- For design of flexible risers against fretting crack nucleation in nub-groove contacts, with initial application of grease, designers must account for contact geometry conformity, as well as normal load (contact pressure) and relative (tangential) displacement, based on dynamic riser curvature, for example. A key fretting design recommendation is that nub-groove contact width should be small (i.e. low contact conformity) relative to anticipated or predicted contact slip, to ensure effective sustainable (grease) lubrication. This will, in turn, reduce the tribological contribution to fretting fatigue damage and therefore contribute to increased fatigue endurance in the pressure armour layer. However, mechanical damage due to the effect of smaller contact width, and associated higher contact stresses, is likely to have a converse effect and therefore a detailed stress analysis with incorporation of the complex tribological contributions (e.g. dependence of friction and wear on contact conformity) is required. 


\section{Acknowledgements}

The authors would like to thank the Irish Research Council and Wood Group Kenny for funding of this project through the Enterprise Partnership Scheme (EPSPG/2013/638), the National University of Ireland for funding through a NUI Travelling Scholarship. We also wish to acknowledge the help and support we have received from Dr. Adrian Connaire and Mr. Kieran Kavanagh (Wood Group). The authors also wish to acknowledge the support of the Faculty of Engineering at the University of Nottingham where this research was conducted. 


\section{References}

[1] O. Vingsbo, S. Söderberg, On fretting maps, Wear. 126 (1988) 131-147. doi:10.1016/0043-1648(88)90134-2.

[2] J.J. Madge, S.B. Leen, P.H. Shipway, A combined wear and crack nucleationpropagation methodology for fretting fatigue prediction, Int. J. Fatigue. 30 (2008) 15091528. doi:10.1016/j.ijfatigue.2008.01.002.

[3] O. Jin, S. Mall, Effects of slip on fretting behavior: Experiments and analyses, Wear. 256 (2004) 671-684. doi:10.1016/S0043-1648(03)00510-6.

[4] Y. Berthier, L. Vincent, M. Godet, Velocity accommodation in fretting, Wear. 125 (1988) 25-38. doi:10.1016/0043-1648(88)90191-3.

[5] J. Dobromirski, Variables of fretting process: Are there 50 of them?, Stand. Frett. Fatigue Test Methods Equip. (1992) 60-60-7. doi:10.1520/STP25816S.

[6] R.B. Waterhouse, Fretting corrosion, Pergamon Press, Oxford, New York, 1992.

[7] S. Fouvry, C. Paulin, S. Deyber, Impact of contact size and complex gross-partial slip conditions on Ti-6Al-4V/Ti-6Al-4V fretting wear, Tribol. Int. 42 (2009) 461-474. doi:10.1016/j.triboint.2008.08.005.

[8] R. Merhej, S. Fouvry, Contact size effect on fretting wear behaviour: Application to an AISI 52100/AISI 52100 interface, Lubr. Sci. 21 (2009) 83-102. doi:10.1002/ls.74.

[9] A.R. Warmuth, P.H. Shipway, W. Sun, Fretting wear mapping: the influence of contact geometry and frequency on debris formation and ejection for a steel-on-steel pair, Proc. R. Soc. A Math. Phys. Eng. Sci. 471 (2015) $20140291-20140291$. doi:10.1098/rspa.2014.0291.

[10] J.J. Madge, S.B. Leen, I.R. McColl, P.H. Shipway, Contact-evolution based prediction of fretting fatigue life: Effect of slip amplitude, Wear. 262 (2007) 1159-1170. doi:10.1016/j.wear.2006.11.004.

[11] V. Popov, Method of reduction of dimensionality in contact and friction mechanics: A linkage between micro and macro scales, Friction. 1 (2013) 41-62. doi:10.1007/s40544013-0005-3.

[12] D.A. Hills, A. Sackfield, R.J.H. Paynter, Simulation of fretting wear in halfplane geometries: Part 1-The solution for long term wear, J. Tribol. 131 (2009) 31401. doi:10.1115/1.3118785.

[13] J. Ding, I.R. McColl, S.B. Leen, P.H. Shipway, A finite element based approach to simulating the effects of debris on fretting wear, Wear. 263 (2007) 481-491. doi:10.1016/j.wear.2006.12.056.

[14] I.R. McColl, R.B. Waterhouse, S.J. Harris, M. Tsujikawa, Lubricated fretting wear of a high-strength eutectoid steel rope wire, Wear. 185 (1995) 203-212. doi:10.1016/00431648(95)06616-0.

[15] M. Shima, H. Suetake, I.R. McColl, R.B. Waterhouse, M. Takeuchi, On the behaviour of an oil lubricated fretting contact, Wear. 210 (1997) 304-310. doi:10.1016/S00431648(97)00078-1. 
[16] Z.. Zhou, L. Vincent, Lubrication in fretting - a review, Wear. 225 (1999) 962-967. doi:10.1016/S0043-1648(99)00038-1.

[17] Z.R. Zhou, P. Kapsa, L. Vincent, Grease lubrication in fretting, J. Tribol. 120 (1998) 737-743. doi:10.1115/1.2833773.

[18] L. Haviez, S. Fouvry, R. Toscano, G. Yantio, An energy-based approach to understand the effect of fretting displacement amplitude on grease-lubricated interface, Wear. 338339 (2015) 422-429. doi:10.1016/j.wear.2015.07.015.

[19] K. Wright, An investigation of fretting corrosion, Proc. Inst. Mech. Eng. Part B J. Eng. Manuf. 1 (1952) 556-574. https://scholar.google.com/scholar?q=an+investigation+of+fretting+corrosion+wright $\& b \operatorname{tnG}=\& h l=e n \& a s \_s d t=0 \% 2 \mathrm{C} 5 \# 0$ (accessed January 26, 2016).

[20] A. Neyman, J. Sikora, Grease effect on fretting wear of mild steel, Ind. Lubr. Tribol. 60 (2008) 67-78. doi:10.1108/00368790810858368.

[21] Z. a. Wang, Z.R. Zhou, G.X. Chen, An investigation of palliation of fretting wear in gross slip regime with grease lubrication, Ind. Lubr. Tribol. 63 (2011) 84-89. doi:10.1108/00368791111112207.

[22] H. Lange, S. Berge, Material selection in the offshore industry, MARINTEK, SINTEF Materials and Chemistry, 2004.

[23] S.A. Lotveit, R. Bjaerum, Second generation analysis tool for flexible pipes, in: Proc. Second Eur. Conf. Flex. Pipes, Umbilicals Mar. Cables-Structural Mech. Test., Bentham, London, 1994.

[24] R.N. Burke, J.A. Witz, Fretting fatigue of flexible pipe pressure armour, in: Proc. Third Eur. Conf. Flex. Pipes, Unbilicals Mar. Cables - Mater. Util. Cycl. Therm. Load., Bentham Press, 1995.

[25] J.J. Féret, C.L. Bournazel, Calculation of stresses and slip in structural layers of unbonded flexible pipes, J. Offshore Mech. Arct. Eng. 109 (1987) 263. doi:10.1115/1.3257019.

[26] J.F. McNamara, Three-dimensional analytical simulation of flexible pipe wall structure, J. Offshore Mech. Arct. Eng. 114 (1992) 69-75. doi:10.1115/1.2919961.

[27] A.M. Harte, J.F. McNamara, Modeling porcedured for stress analysis of flexible pipe cross sections, J. Offshore Mech. Artic Eng. 115 (1993) 46-51. doi:10.1115/1.2920088.

[28] S.D.R. Perera, U.S. Fernando, T. Sheldrake, R. Clements, An investigation into fretting behaviour in pressure armor wires of unbonded flexible pipes, in: Vol. 3 Pipeline Riser Technol. CFD VIV, San Diego, California, USA, 2007: pp. 363-370. doi:10.1115/OMAE2007-29393.

[29] S.M. O'Halloran, A.D. Connaire, A.M. Harte, S.B. Leen, Modelling of fretting in the pressure armour layer of flexible marine risers, Tribol. Int. 100 (2016) 306-316. doi:10.1016/j.triboint.2016.02.040.

[30] S.M. O'Halloran, P.H. Shipway, A.D. Connaire, S.B. Leen, A.M. Harte, A combined wear-fatigue design methodology for fretting in the pressure armour layer of flexible marine risers, Tribol. Int. 108 (2017) 7-15. doi:10.1016/j.triboint.2016.10.020. 
[31] S.M. O'Halloran, A.M. Harte, A.D. Connaire, S.B. Leen, Implementation of fretting wear-fatigue model for global - local analysis of nub-groove contact for flexible marine riser design, (2017). doi:To be submitted.

[32] ASTM International, ASTM D4170-10 Standard test method for fretting wear protection by lubricating greases, (2010). doi:10.1520/D4170-10.

[33] ASTM International, ASTM D7594-11 Standard test method for determining fretting wear resistance of lubricating greases under high Hertzian contact pressure using a highfrequency, linear-oscillation (SVR) test machine, (2011). doi:10.1520/D7594-11.

[34] S.R. Pearson, The effect of nitriding on the fretting wear of a high strength steel at ambient and elevated temperatures, (Ph.D. Thesis) University of Nottingham, 2013.

[35] X. Jin, P.H. Shipway, W. Sun, The role of frictional power dissipation (as a function of frequency) and test temperature on contact temperature and the subsequent wear behaviour in a stainless steel contact in fretting, Wear. 330 (2015) 103-111. doi:10.1016/j.wear.2015.02.022.

[36] C.A. Coulomb, Théorie des machines simples, en ayant égard au frottement de leurs parties, et a la roideur des cordages, Bachelier, Paris, 1785. https://books.google.dz/books/about/Théorie_des_machines_simples.html?id=XmQJA AAAIAAJ\&pgis $=1$.

[37] S. Fouvry, P. Duó, P. Perruchaut, A quantitative approach of Ti-6Al-4V fretting damage: Friction, wear and crack nucleation, Wear. 257 (2004) 916-929. doi:10.1016/j.wear.2004.05.011.

[38] X. Jin, W. Sun, P.H. Shipway, Derivation of a wear scar geometry-independent coefficient of friction from fretting loops exhibiting non-Coulomb frictional behaviour, Tribol. Int. 102 (2016) 561-568. doi:10.1016/j.triboint.2016.06.012.

[39] K. Elleuch, S. Fouvry, Wear analysis of A357 aluminium alloy under fretting, Wear. 253 (2002) 662-672. doi:10.1016/S0043-1648(02)00116-3.

[40] P. Blau, Glossary of terms, Frict. Lubr. Wear Technol. ASM Handb. 18 (1998) 1-21.

[41] C.H. Hager, J. Sanders, S. Sharma, A. Voevodin, A. Segall, The effect of temperature on gross slip fretting wear of cold-sprayed nickel coatings on Ti6Al4V interfaces, Tribol. Int. 42 (2009) 491-502. doi:10.1016/j.triboint.2008.08.009.

[42] E.O. Doebelin, Measurement systems: application and design, Tata McGraw Hill Education Private Limited, New Delhi (India), 1975.

[43] A.R. Warmuth, W. Sun, P.H. Shipway, The roles of contact conformity, temperature and displacement amplitude on the lubricated fretting wear of a steel-on-steel contact, R. Soc. Open Sci. 3 (2016). doi:10.1098/rsos. 150637.

[44] O. Jin, S. Mall, Influence of contact configuration on fretting fatigue behaviour of Ti$6 \mathrm{Al}-4 \mathrm{~V}$ under independent pad displacement condtions, Internaltional J. Fatigue. 24 (2002) 1243-1253.

[45] T. Zhang, P.E. Mchugh, S.B. Leen, Computational study on the effect of contact geometry on fretting behaviour, Wear. 271 (2011) 1462-1480. doi:10.1016/j.wear.2010.11.017. 
[46] N.M. Everitt, J. Ding, G. Bandak, P.H. Shipway, S.B. Leen, E.J. Williams, Characterisation of fretting-induced wear debris for Ti-6Al-4 V, Wear. 267 (2009) 283291. doi:10.1016/j.wear.2008.12.032.

[47] P. Arnaud, S. Fouvry, S. Garcin, A numerical simulation of fretting wear profile taking account of the evolution of third body layer, Wear. (2017). doi:10.1016/j.wear.2017.01.063.

[48] S. Fouvry, P. Arnaud, A. Mignot, P. Neubauer, Contact size, frequency and cyclic normal force effects on $\mathrm{Ti}-6 \mathrm{Al}-4 \mathrm{~V}$ fretting wear processes: An approach combining friction power and contact oxygenation, Tribol. Int. 113 (2017) 460-473. doi:10.1016/j.triboint.2016.12.049.

[49] S.B. Leen, T.H. Hyde, C.H.H. Ratsimba, E.J. Williams, I.R. McColl, An investigation of the fatigue and fretting performance of a representative aero-engine spline coupling, J. Strain Anal. Eng. Des. 37 (2002) 565-583. doi:10.1243/030932402320950161.

[50] D. Houghton, P.M. Wavish, E.J. Williams, S.B. Leen, Multiaxial fretting fatigue testing and prediction for splined couplings, Int. J. Fatigue. 31 (2009) 1805-1815. doi:10.1016/j.ijfatigue.2008.12.005.

[51] P.M. Wavish, D. Houghton, J. Ding, S.B. Leen, E.J. Williams, I.R. McColl, A multiaxial fretting fatigue test for spline coupling contact, Fatigue Fract. Eng. Mater. Struct. 32 (2009) 325-345. doi:10.1111/j.1460-2695.2009.01334.x.

[52] C.H.H. Ratsimba, I.R. McColl, E.J. Williams, S.B. Leen, H.P. Soh, Measurement, analysis and prediction of fretting wear damage in a representative aeroengine spline coupling, Wear. 257 (2004) 1193-1206. doi:10.1016/j.wear.2004.08.003. 


\section{Figures}

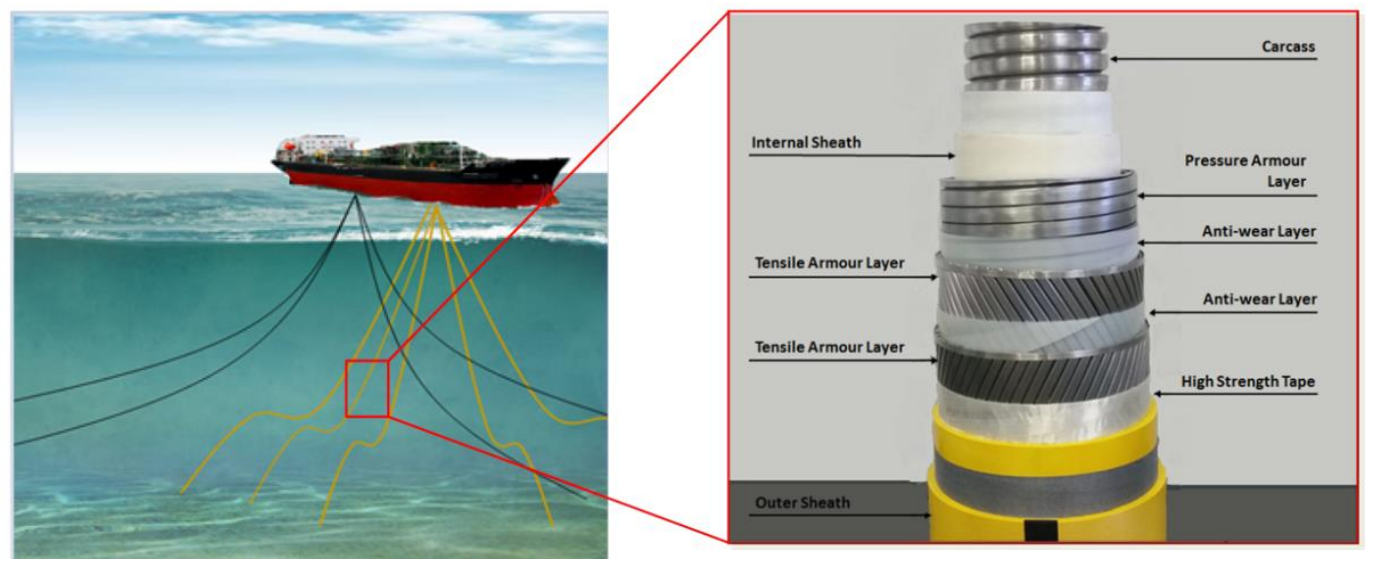

Figure 1. Schematic of global flexible riser, cross-section of flexible marine riser.

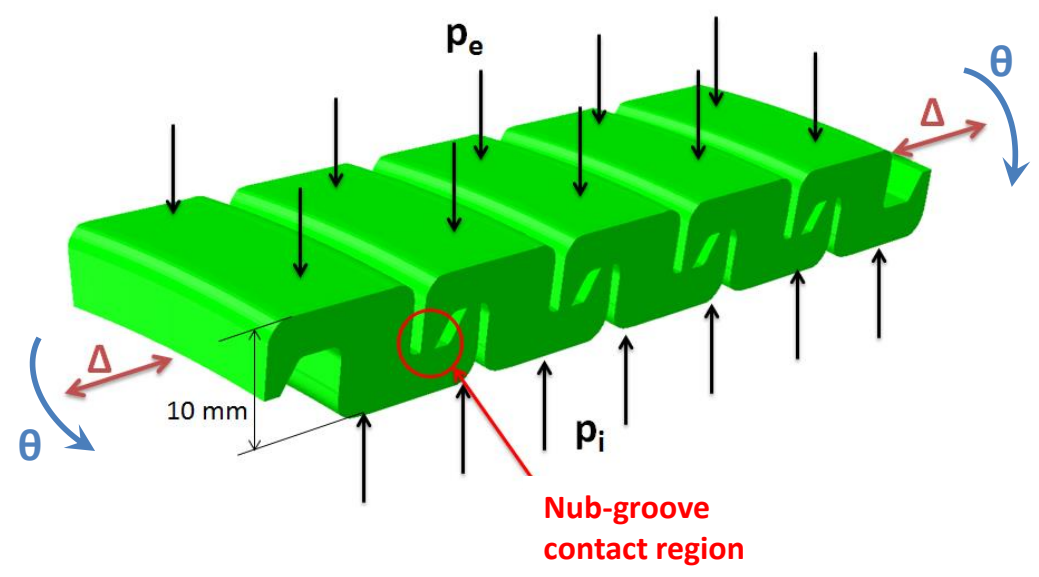

Figure 2. Schematic of pressure armour layer geometry and loading conditions. 


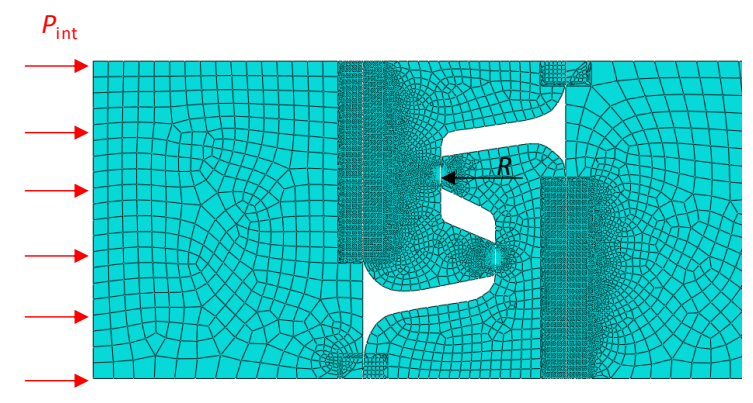

(a)

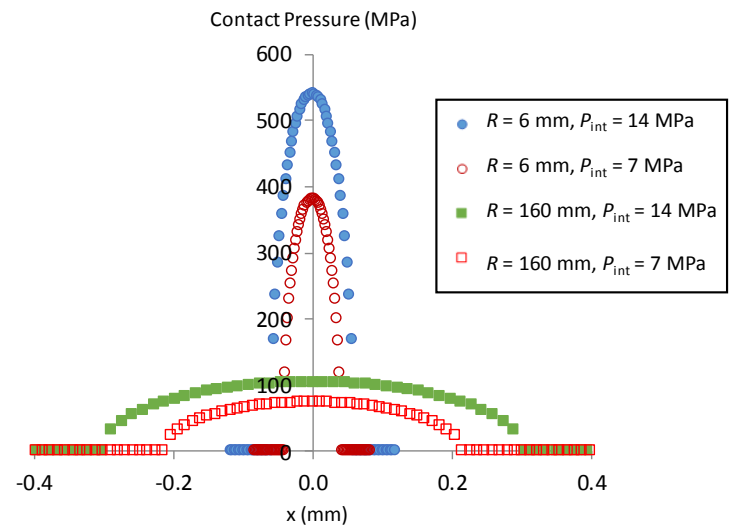

(b)

Figure 3. (a) Axisymmetric finite element of pressure armour fretting contact, (b) nubgroove contact pressure distribution [29].
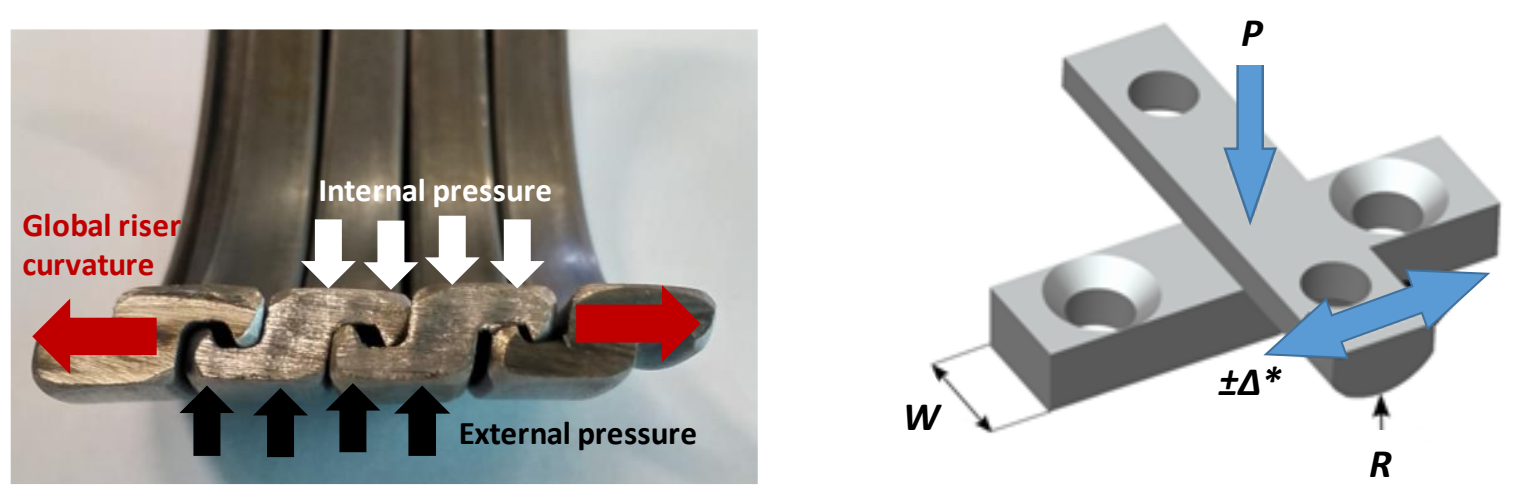

Figure 4. Local nub-groove conditions represented as crossed cylinder-on-flat specimen configuration utilised in fretting tests. 


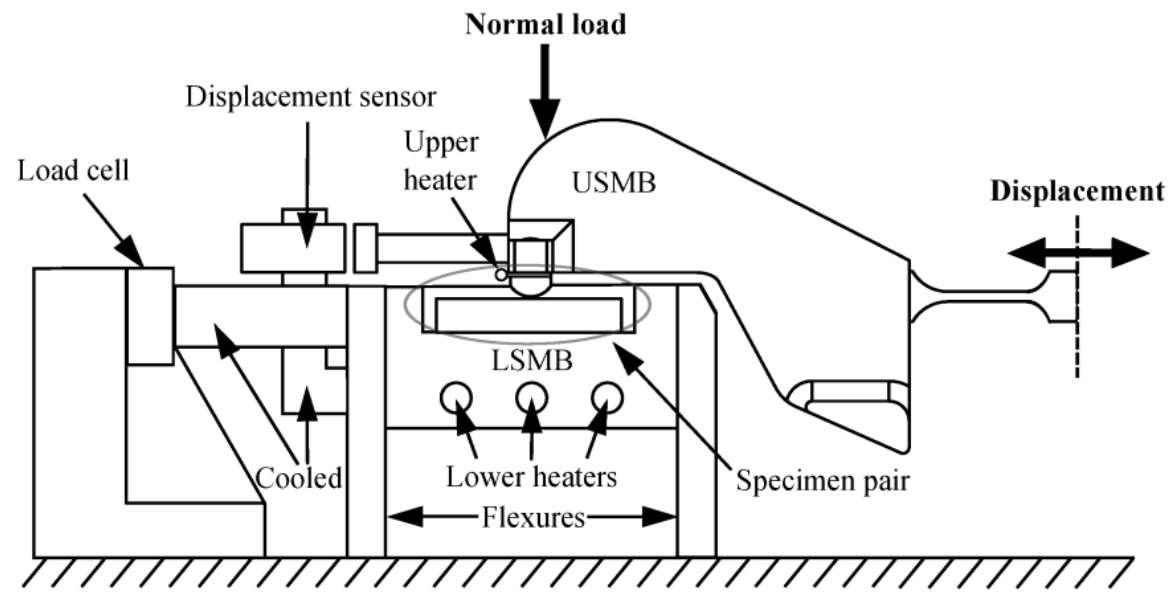

Figure 5. Illustration of the main components of the fretting apparatus used in this study [34].

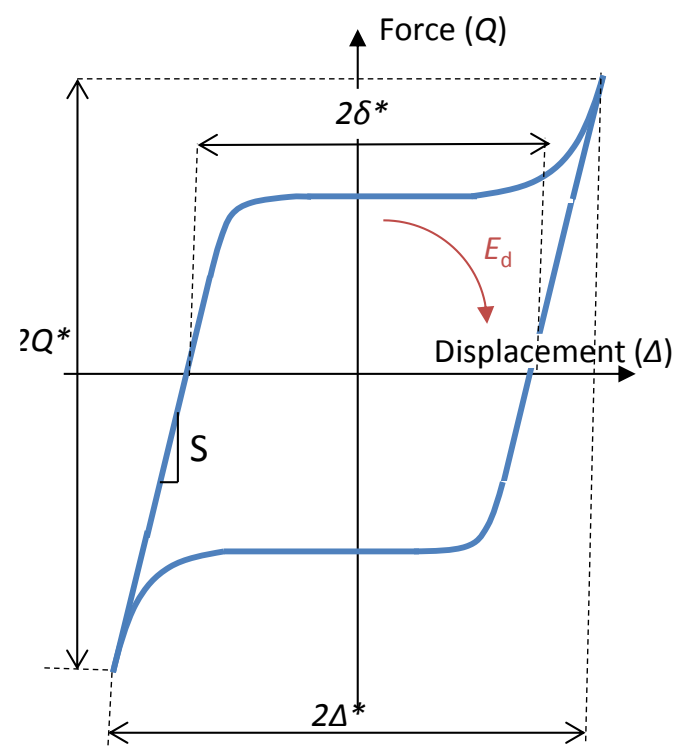

Figure 6. Schematic diagram of fretting loop with high tractional force peak at the ends of gross sliding. 
Cylindrical specimen

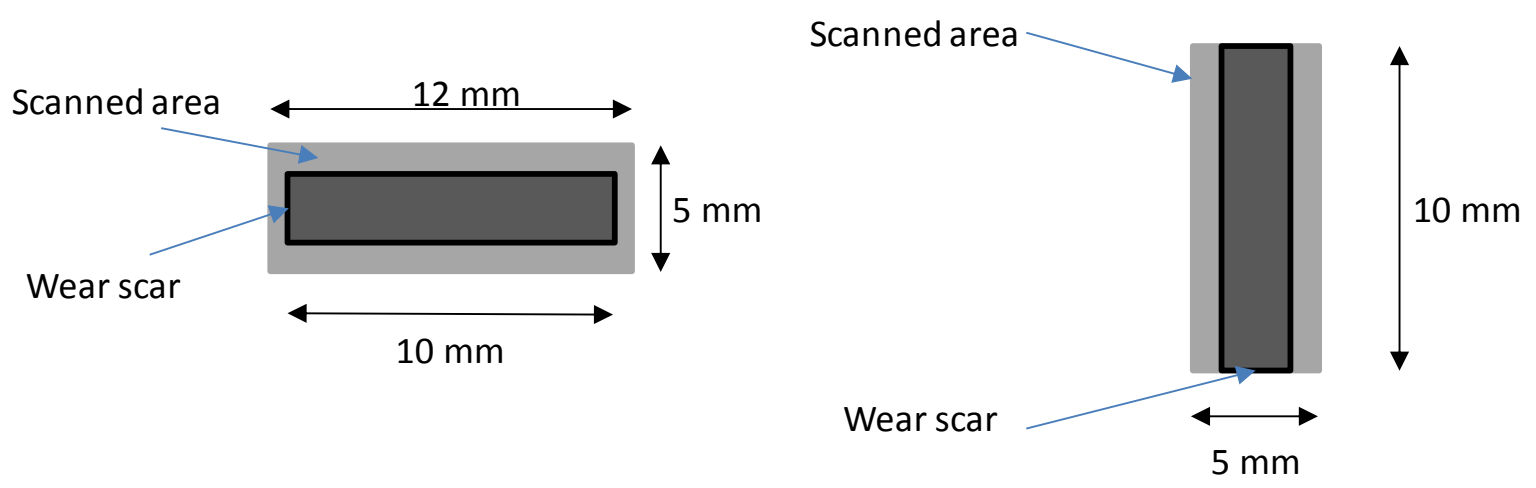

Figure 7. Illustration of the area measured by profilometry with respect to the fretting wear scar.

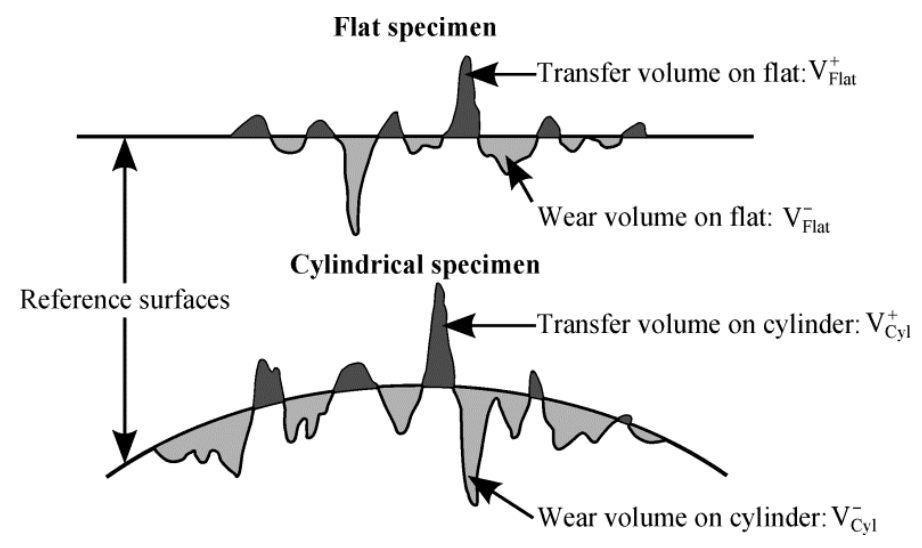

Figure 8. Illustration of the definition of wear and transfer volumes in a fretting scar for both the flat and cylindrical specimen [43]. 


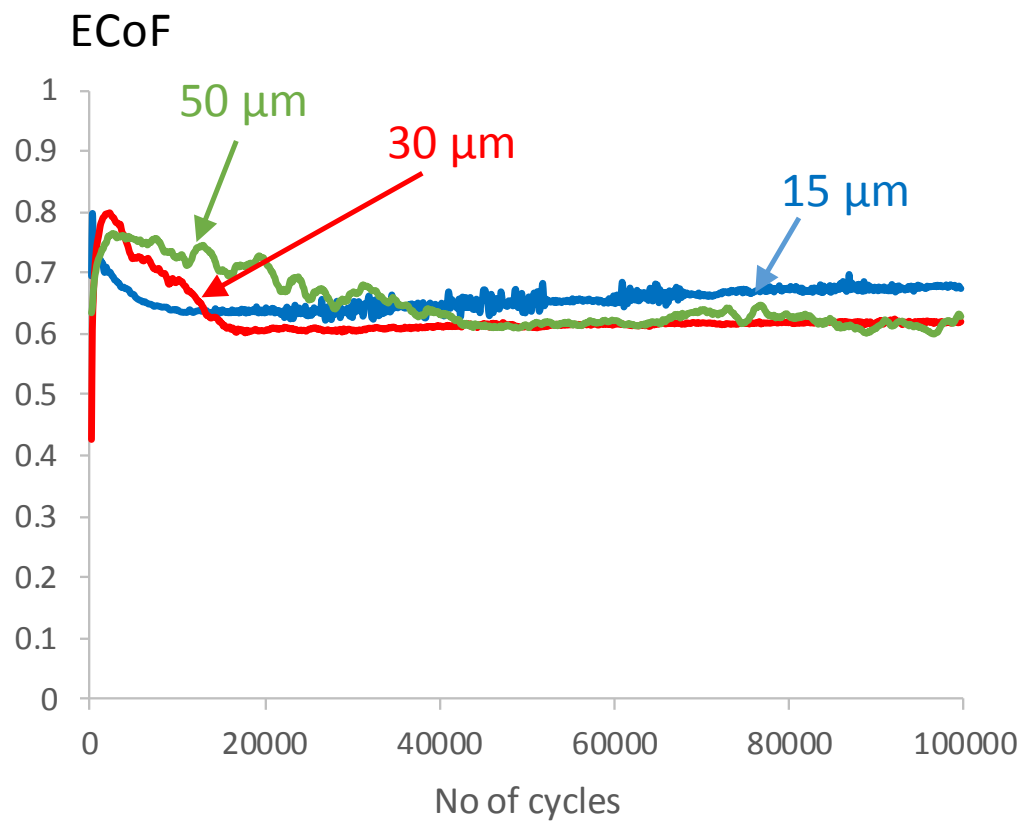

Figure 9. Plots of development of ECoF with number of fretting cycles for dry fretting contacts with cylinders of radius $6 \mathrm{~mm}$, applied displacements of 15, 30 and $50 \mu \mathrm{m}$ and normal load of $250 \mathrm{~N}$. 
(a) $P=250 \mathrm{~N}$

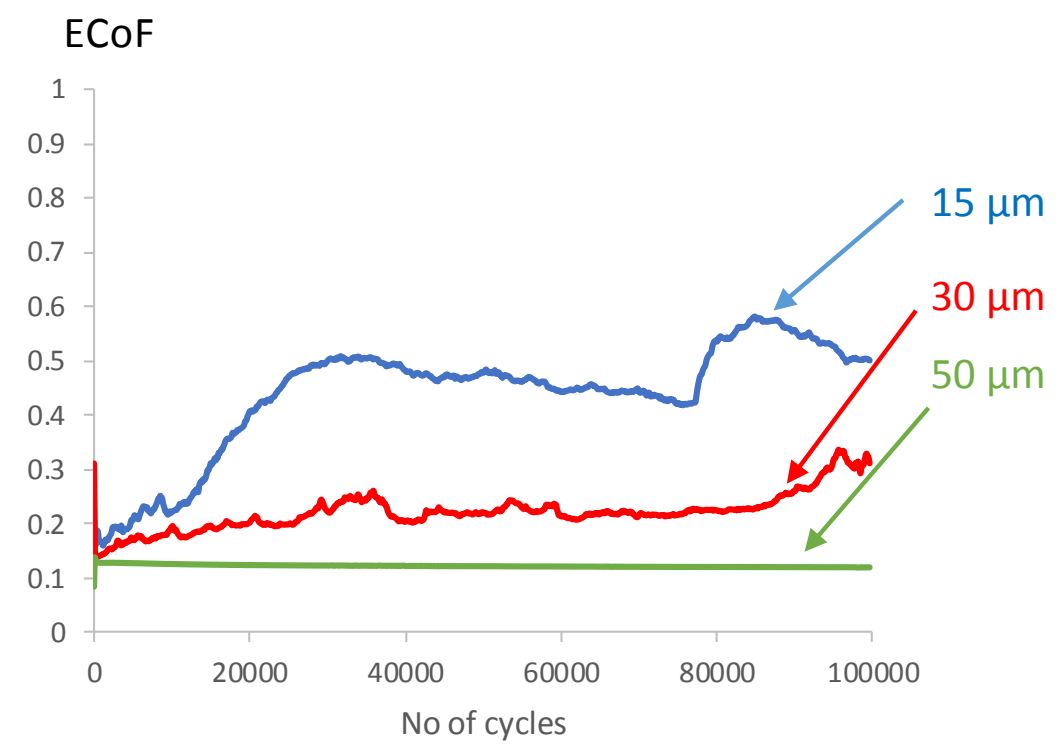

(b) $P=500 \mathrm{~N}$

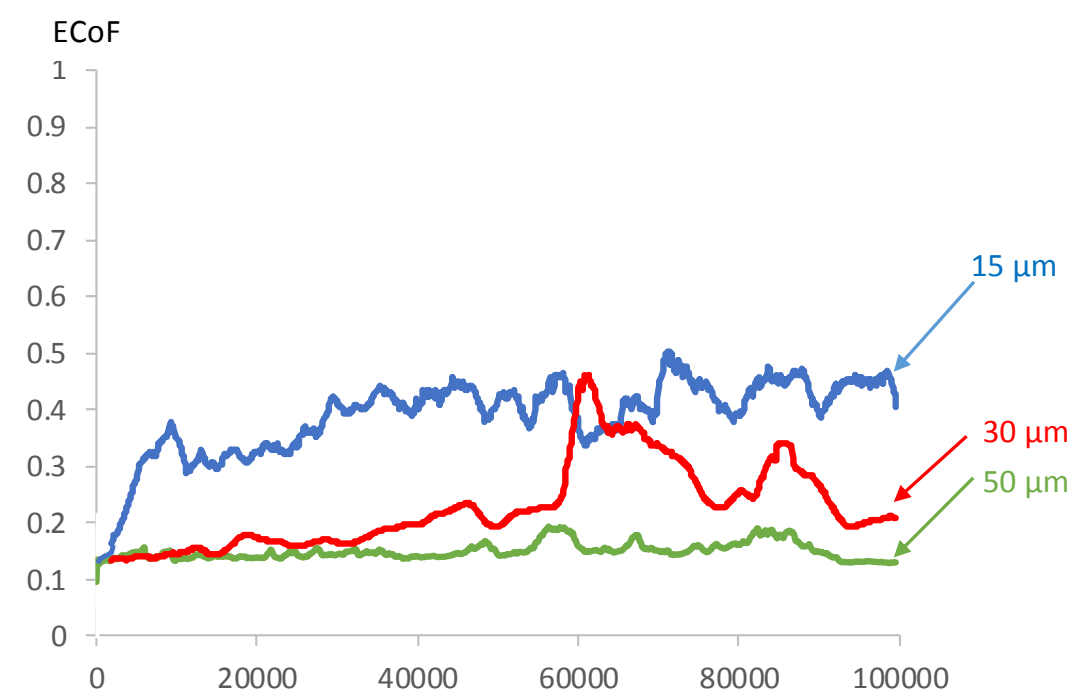

Figure 10. Effect of tangential displacement on evolution of ECoF with number of fretting cycles for grease-lubricated contact, with cylinder of radius $6 \mathrm{~mm}$ and normal loads of (a) $250 \mathrm{~N}$ and (b) $500 \mathrm{~N}$. 
(a) $P=250 \mathrm{~N}$

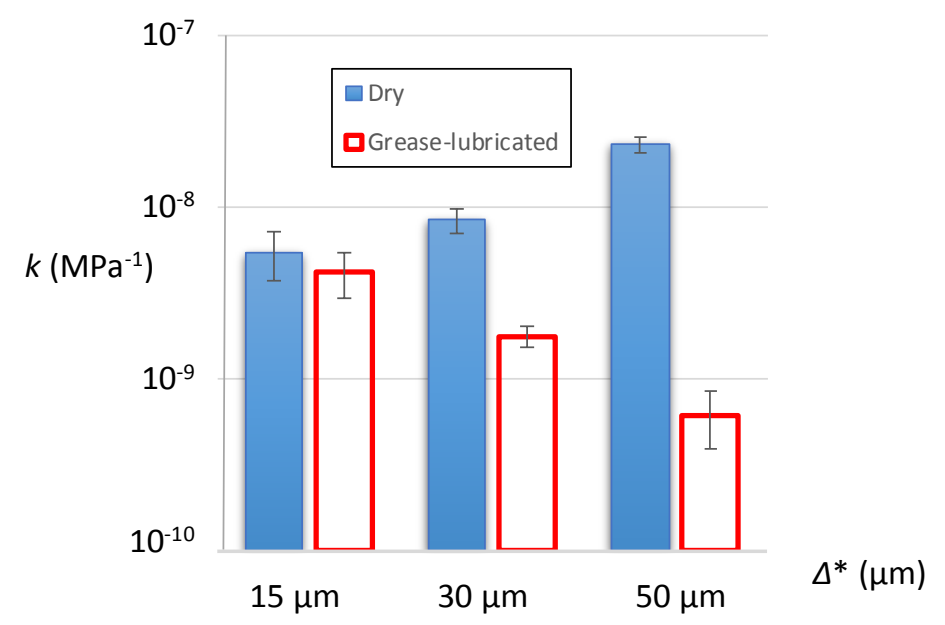

(b) $P=500 \mathrm{~N}$

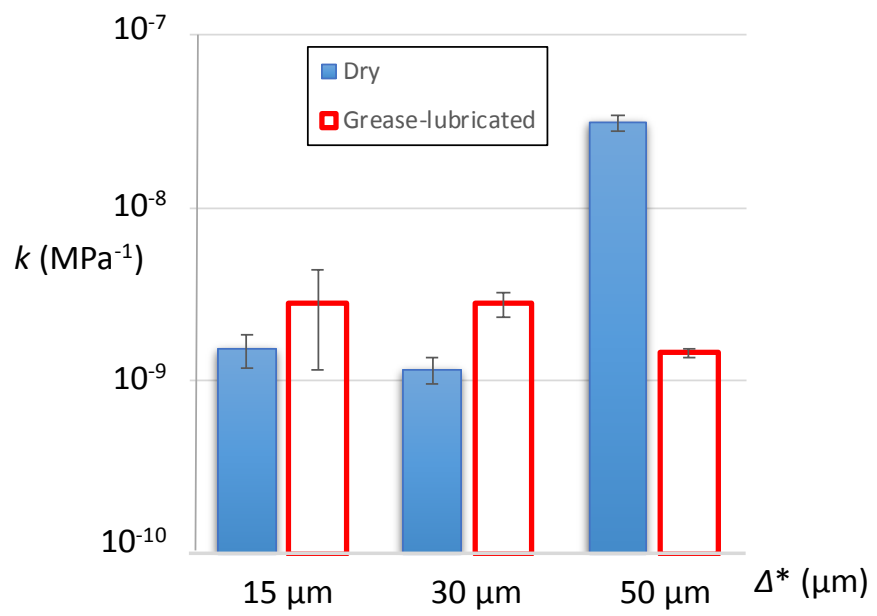

Figure 11. Specific wear rate, $k$, including error bars calculated from Equation 9, for dry and grease-lubricated tests with cylinder of radius $6 \mathrm{~mm}$, an applied displacement of $\Delta^{*}$ and normal loads of (a) $250 \mathrm{~N}$, and (b) $500 \mathrm{~N}$. 


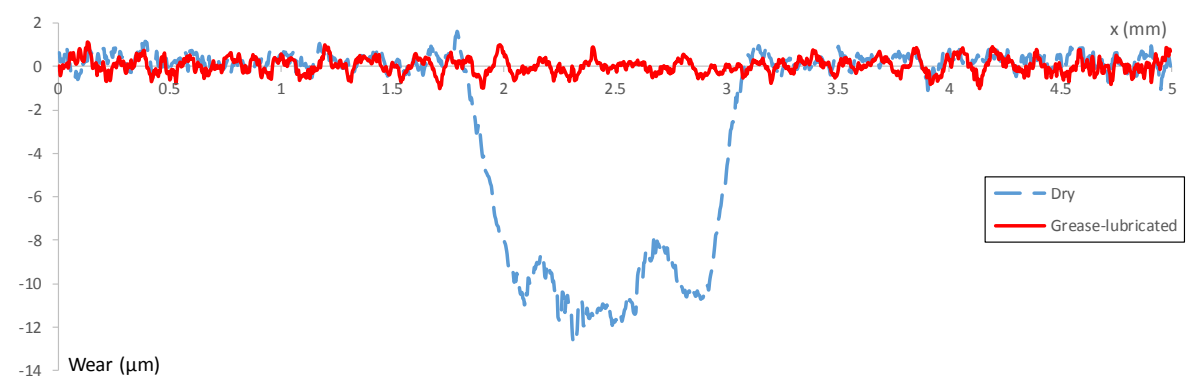

(a) Wear profiles

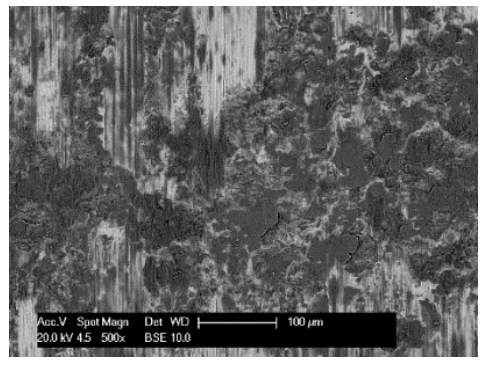

(b) Dry

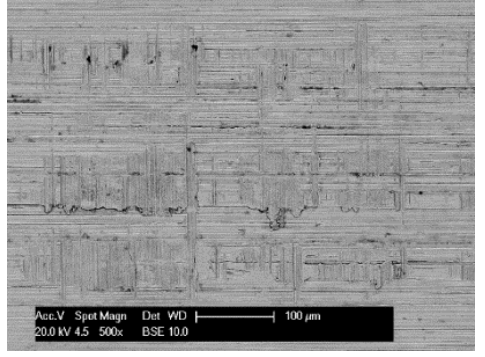

Direction

of stroke

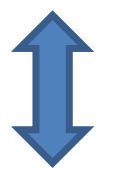

(c) Grease-lubricated

Figure 12. (a) Wear profiles and (b, c) BSE images (plan view) of the flat specimen wear scars at high magnification for cylinder radius $6 \mathrm{~mm}$, normal load $250 \mathrm{~N}$ and applied displacement $50 \mu \mathrm{m}$, under dry and grease-lubricated conditions. 
(a) $P=250 \mathrm{~N}$

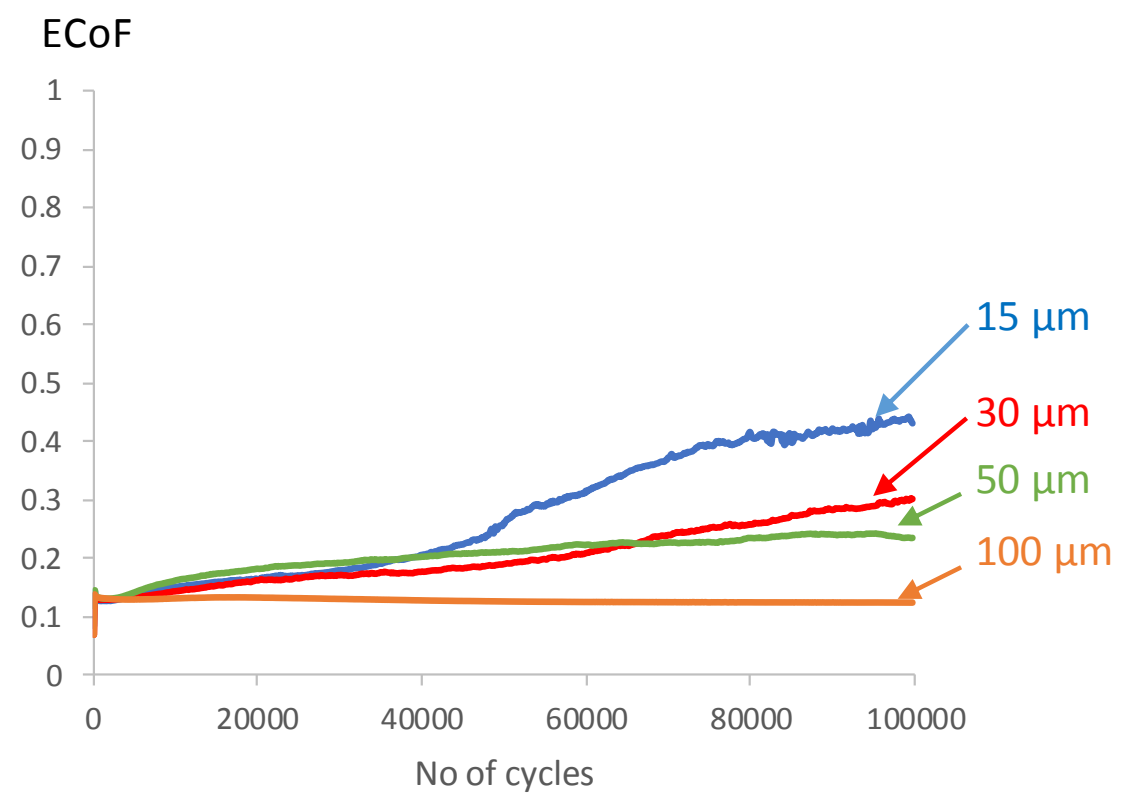

(b) $P=500 \mathrm{~N}$

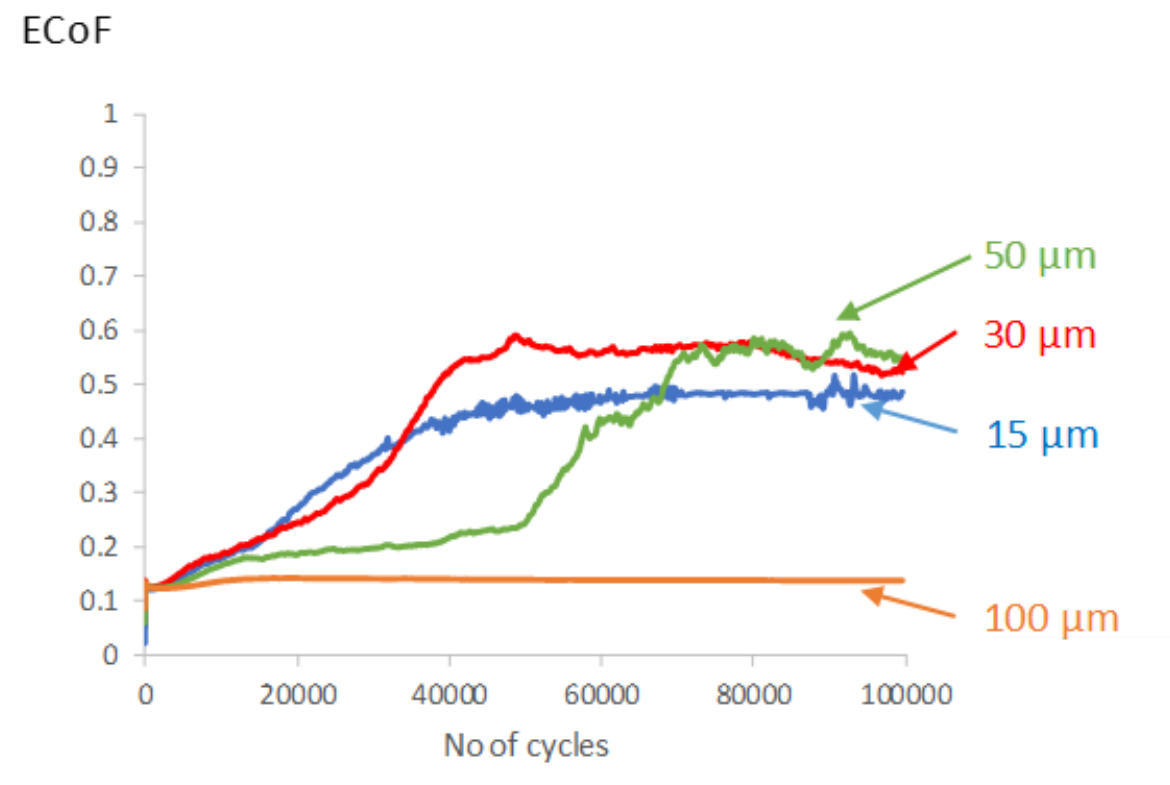

Figure 13. Effect of tangential displacement on evolution of ECoF with number of fretting cycles for grease-lubricated contact, with radius $160 \mathrm{~mm}$ and normal loads of (a) $250 \mathrm{~N}$ and (b) $500 \mathrm{~N}$. 
(a) $P=250 \mathrm{~N}$

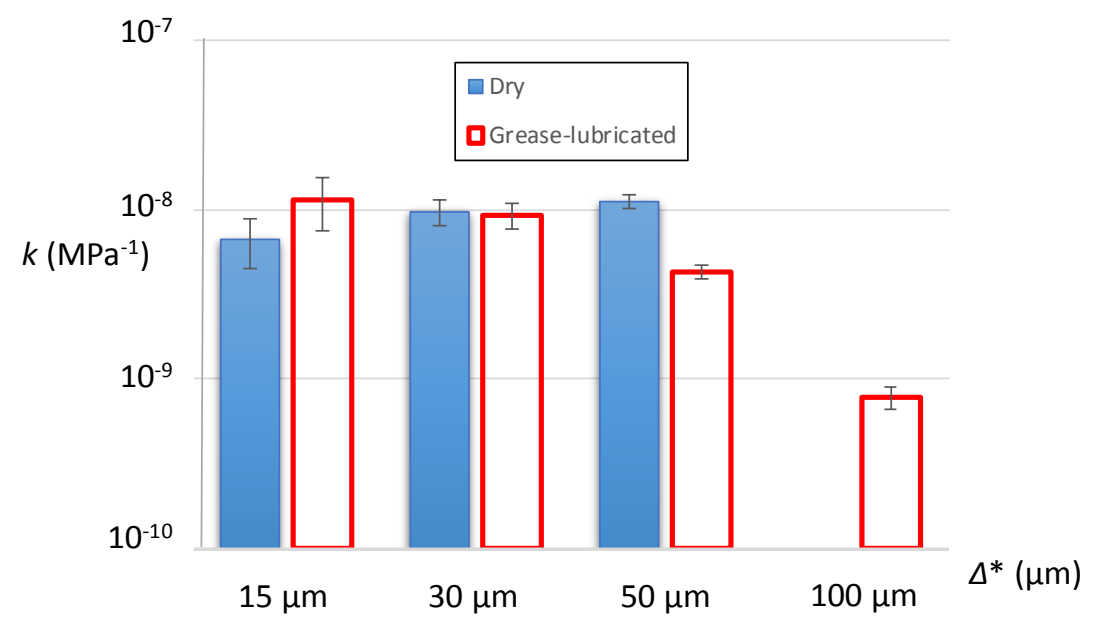

(b) $P=500 \mathrm{~N}$

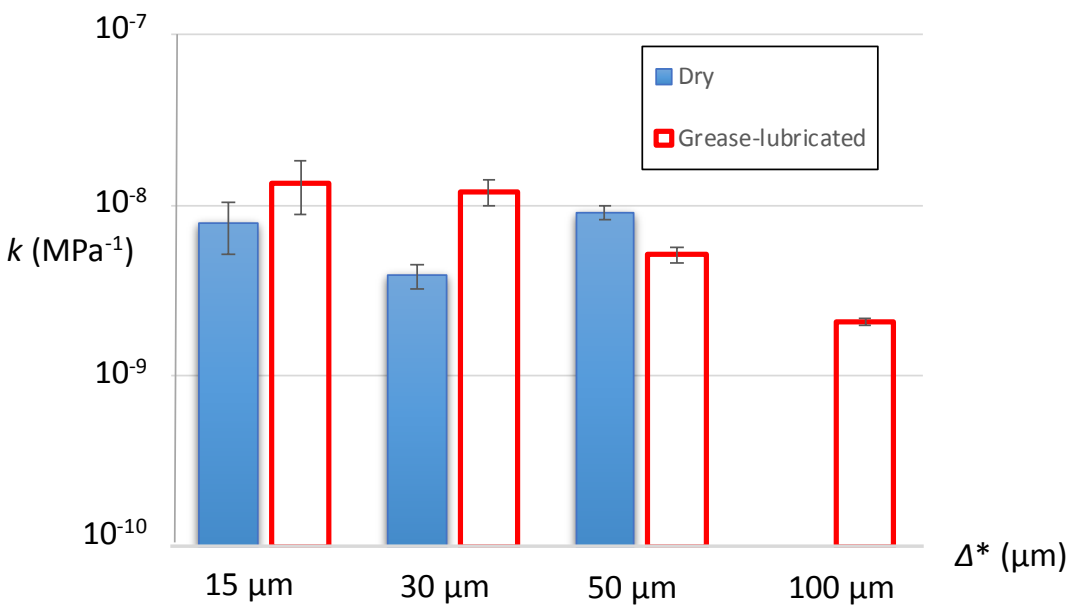

Figure 14. Specific wear rate, $k$, including error bars calculated from Equation 9, for dry and grease-lubricated tests with cylinder of radius $160 \mathrm{~mm}$, an applied displacement of $\Delta^{*}$ normal load of (a) $250 \mathrm{~N}$, and (b) $500 \mathrm{~N}$ for grease-lubricated conditions. 


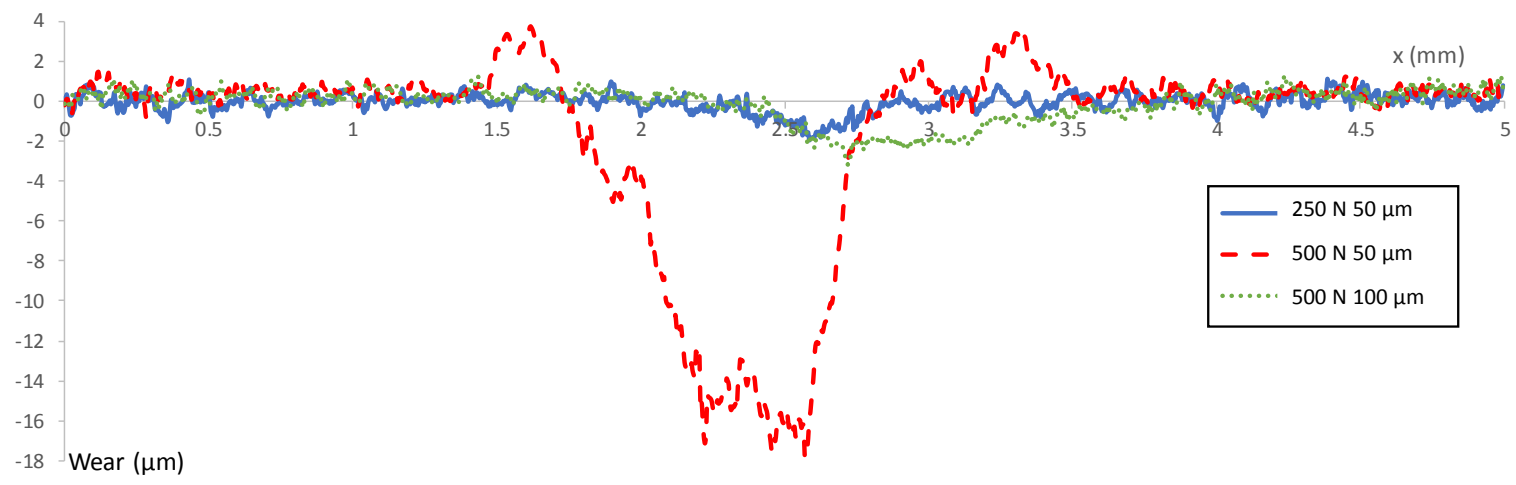

(a) Wear profiles

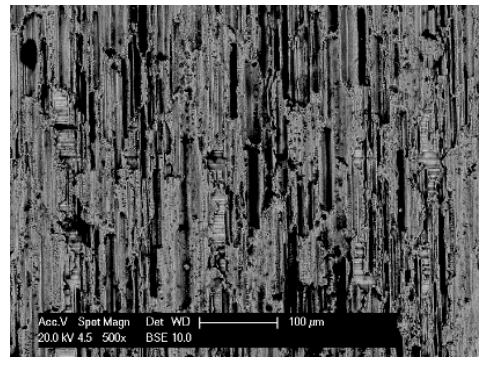

(b) $P=250 \mathrm{~N}, \Delta^{*}=50$ $\mu \mathrm{m}$

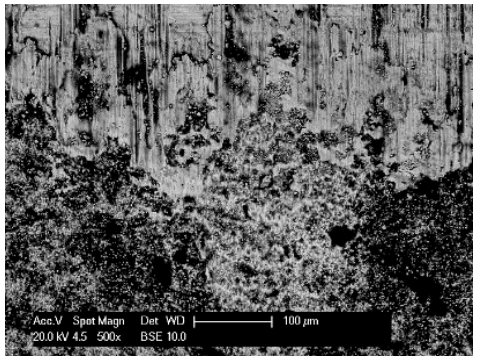

(c) $P=500 \mathrm{~N}, \Delta^{*}=50$

$\mu \mathrm{m}$

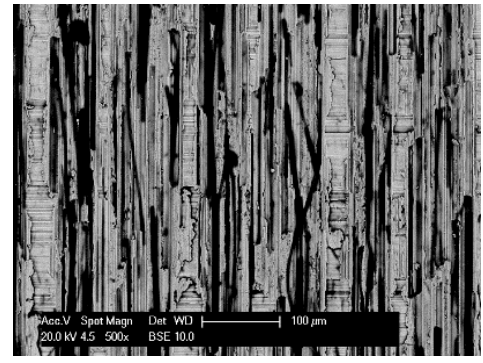

Direction of stroke

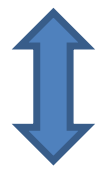

Figure 15. (a) Wear profiles and (b, c, d) BSE images (plan view) of the flat specimen wear scars high magnification for cylinder radius $160 \mathrm{~mm}$ and grease-lubricated conditions. 


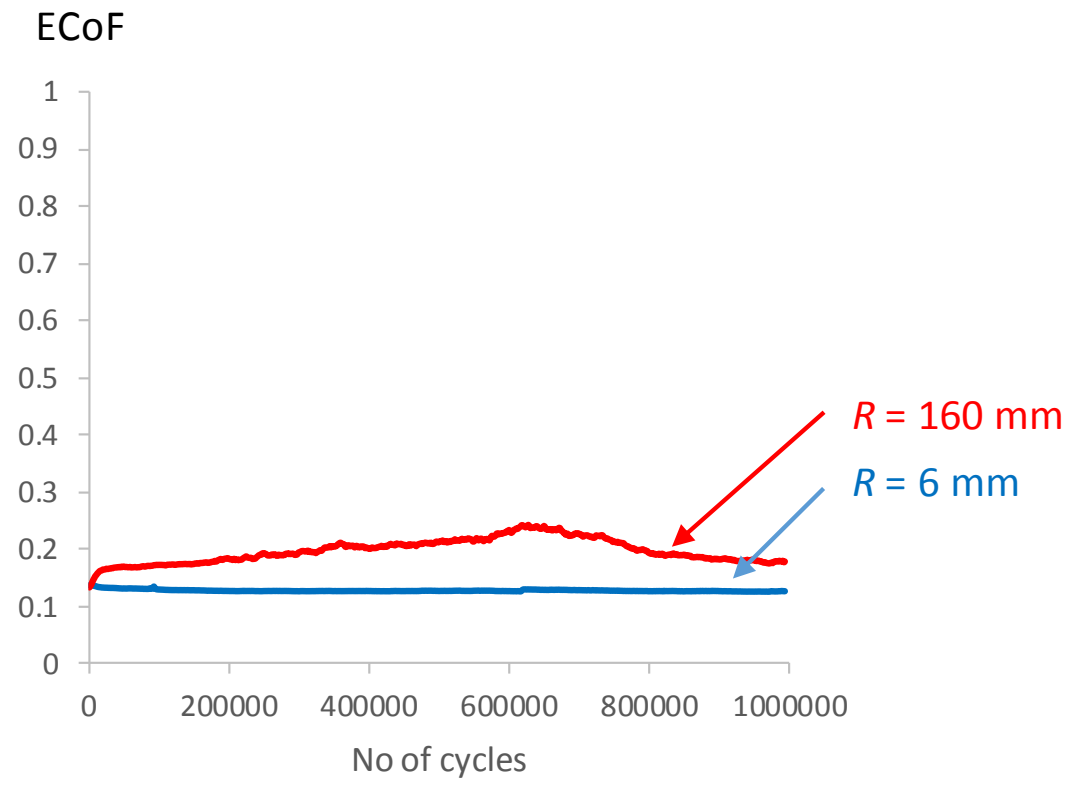

Figure 16. Development of ECoF for extended tests $\left(10^{6}\right.$ cycles $)$ for grease-lubricated contact cylinders of radius $R$ with applied displacement $50 \mu \mathrm{m}$ and normal load $250 \mathrm{~N}$. 


\section{Tables}

Table 1. Chemical composition of 080M40 steel (from data sheet).

\begin{tabular}{c|cccccc}
\hline Element & $\mathrm{Fe}$ & $\mathrm{C}$ & $\mathrm{Mg}$ & $\mathrm{Si}$ & $\mathrm{P}$ & $\mathrm{S}$ \\
& & & & & & \\
\hline Weight (\%) & Balance & $0.36-0.44$ & $0.60-1.00$ & $0.10-0.40$ & 0.050 Max & 0.050 Max \\
& & & & & & \\
\hline
\end{tabular}

Table 2. Summary of the fretting test parameters.

\begin{tabular}{l|l}
\hline Lubricant temperature & Ambient \\
Cylinder radii, $\boldsymbol{R}$ & $6,160 \mathrm{~mm}$ \\
Displacement amplitudes, $\boldsymbol{A}^{*}$ & $15,30,50,100 \mu \mathrm{m}$ \\
Test duration, $\boldsymbol{N}$ & 100,000 cycles \\
Normal load, $\boldsymbol{P}$ & $250,500 \mathrm{~N}$ \\
Oscillation frequency & $20 \mathrm{~Hz}$ \\
Lubricant & Dry, Li-based grease \\
\hline
\end{tabular}

